\title{
Получение ионных кластеров аминокислот в присутствии сульфата меди в условиях полевой ионизации их водно-ацетонитрильных растворов
}

\author{
Кузнецова Е.С., Пыцкий И.С., Буряк А.К. \\ Федеральное Государственное Бюджетное Учреждение Науки \\ Институт физической химии и электрохимии имени А.Н. Фрумкина РАН, Москва
}

Поступила в редакцию 29.06.2018 г.

DOI: https://doi.org/10.17308/sorpchrom.2018.18/601

\begin{abstract}
Проведено систематическое исследование ионизации аминокислот методом ионизации электрораспылением (ESI-MS) в присутствии соли меди. Проведено исследование влияния состава подвижной фазы на качество и состав масс-спектров. Состав смеси ацетонитрил-вода варьировался от 5 до 95\% воды. Установлено, что изменение состава подвижной фазы существенно не влияет на состав масс-спектра. Качество масс-спектра значительно зависит от чистоты используемого ацетонитрила, который в больших количествах увеличивает химический шум и затрудняет идентификацию. Наилучшим для работы соотношением было 70\% воды и $30 \%$ ацетонитрила. Показано, что для ароматических аминокислот (тирозина, триптофана) наиболее характерны процессы фрагментации молекулы аминокислоты такие как декарбоксилирование, деаминирование, дегидратирование. Процессы кластерообразования в значительной степени подавлены. На примере пролина показано, что наиболее интенсивно кластерообразование проходит в простых неароматических аминокислотах. Видно, что кластерообразование в таких случаях идёт по трём различным направлениям: образование молекулярных ассоциатов аминокислот с несущим заряд протоном, образование молекулярных ассоциатов аминокислот с несущим заряд атомом меди и образование полимолекулярных координированных структур, координируемых двумя ионами меди. В работе показано, что результаты полученные при исследовании могут быть использованы для более чувствительного и информативного поиска аминокислот в растворах сложных смесей с хроматографическим разделением и при использовании прямого ввода.
\end{abstract}

Ключевые слова: масс-спектрометрия, сульфат меди, кластерообразование, аминокислоты, ионизация электрораспылением, катионирование, ионные кластеры.

\section{Preparation of ionic clusters of amino acids in the copper sulfate presence under the field ionization of their water-acetonitrile solutions conditions}

\author{
Kuznetsova E.S., Pytskii I.S., Buryak A.K. \\ Institute of Physical Chemistry and Electrocemistry RAS (IPCE RAS), Moscow
}

A systematic study of ionization of amino acids by the method of electrospray ionization (ESI-MS) in the name of salt was carried out. The influence of the composition of the mobile phase on the quality and composition of the mass spectra was studied. The composition of the acetonitrile-water mixture varied from 5 to $95 \%$ water. It is established that the change in the composition of the mobile phase does not significantly affect the composition of the mass spectrum. The best ratio for work was $70 \%$ water and $30 \%$ acetonitrile. The quality of the mass spectrum significantly depends on the purity of the acetonitrile used, which in large quantities increases the chemical noise and makes identification difficult. It is shown that for aromatic amino 
acids (tyrosine, tryptophan), the processes of amino acid molecule fragmentation, such as decarboxylation, deamination, dehydration are most characteristic. The processes of cluster formation in freedom are suppressed. Using proline as an example, it was shown that cluster formation occurs most often in simple nonaromatic amino acids.

It is seen that cluster formation in such cases proceeds in three different directions: the formation of molecular associates of amino acids with a charge carrying a proton, the formation of molecular associates of amino acids with a charge-carrying copper atom and the formation of polymolecular coordinated structures coordinated by two copper ions. It is shown that the results obtained in the study can be used for a more sensitive and informative search for amino acids in solutions of complex mixtures with chromatographic separation and when using direct input.

Keywords: mass spectrometry, copper sulfate, clustering, amino acids, electrospray ionization, cationization, ion clusters

\section{Введение}

Изучение физико-химических процессов при ионизации различными способами является важным направлением исследований в современной науке [1-2]. Одним из популярных методов подобных исследований является матричноактивированная лазерная десорбция/ионизация (МАЛДИ). Наиболее полно эти процессы описаны в [3]. Кроме этого, авторами проведён ряд исследований по изучению ионизации различных солей и органических соединений [4,5]. Альтернативным методом исследования кластерообразования является метод электрораспыления ESIMS. Этот метод является также «мягким», но в отличие от МАЛДИ ионизация в нём производится не с поверхности, а из объёма микрокапель находящихся в поле высокой напряжённости. В работе [6] показано, что при высыхании заряженных капель в потоке чистого азота при температуре $200-400^{\circ} \mathrm{C}$ происходит агломерация частиц вокруг заряженного центра с образованием крупных кластерных ионов. В предыдущей работе [5] авторами было показано возможность получения кластерных ионов аминокислот с использованием серебра. В более ранних работах авторов также была показана возможность кластерообразования различных неорганических солей[7-8]. В настоящей работе метод ESI-MS, будет применён для систематического исследования кластерообразования аминкислот в присутствии соли меди. Основной целью при этом является определение основных направлений агломерации аминокислот и идентификация наиболее часто встречающихся кластерных ионов в масс-спектрах, проверка влияния неорганических солей на агломерацию молекул аминокислот в условиях ионизации.

\section{Эксперимент}

Для получения масс-спектров аминокислот в присутствии солей меди использовали масс-спектрометр Bruker Maxis Impact с ионизацией в электроспреe (Bruker, Германия). Состав растворителя вода-ацетонитрил варьировали от 5 до 95\% воды. Скорость потока $-0.25 \mathrm{~cm}^{3} /$ мин, напряжение на капилляре - 4500 В, на скиммере 500 В. Время задержки импульса - 10 мкс. Диапазон исследуемых масс - 50-300 Да. Калибровку по массам проводили с использованием раствора ацетата натрия в воде и изопропаноле (1:1). Ацетат натрия (о.с.ч., Реахим, Россия), Изопропанол (HPLCgrade, JT Baker, США). В качестве модельных объектов исследования использовали набор аминокислот: аланин, пролин, тирозин, триптофан (Sigma Aldrich, США). Сухие аминокислоты растворяли в смеси ацетонитрил-вода (1:1) и получали концентрации аминокислот $10^{-5}-10^{-2} \mathrm{M}$. Сульфат меди растворяли в смеси ацетонитрил-вода (1:1) и получали концентрации меди $10^{-5}-10^{-1}$ M. Все полученные концентрации смесей аминокислот и меди указаны в таблице 1. 
Таблица 1. Использованные растворы солеи и аминокислот. (Смешаны в соотношении 1:1 по объёму).

\begin{tabular}{|c|c|c|c|c|}
\hline \multirow{2}{*}{$\begin{array}{c}\text { Концентрация } \\
\text { Меди в растворе } \\
\text { сульфата меди, М }\end{array}$} & \multicolumn{4}{|c|}{ Концентрация аминокислоты в растворе, М } \\
\hline $10^{-5}$ & $\mathrm{~A} 1$ & $10^{-4}$ & $10^{-3}$ & $10^{-1}$ \\
\hline $10^{-4}$ & Б1 & А2 & А & А \\
\hline $10^{-3}$ & В1 & В2 & Б3 & Б4 \\
\hline $10^{-2}$ & Г1 & Г2 & В3 & В4 \\
\hline $10^{-1}$ & Д1 & Д2 & Д3 & Г4 \\
\hline
\end{tabular}

Кроме того, в работе использовали воду milli-Q, ацетонитрил JT Baker, США). Все полученные растворы были исследованы методом ESI-MS в режиме регистрации и положительных и отрицательных ионов.

\section{Обсуждение результатов}

При исследовании приготовленных растворов было показано, что растворы A1-A4 дают неинформативные спектры в обоих полярностях, кроме того невозможно производить расшифровку масс-спектров растворов Г4, Д3 и Д4 в связи с высоким химическим шумом и наличием высокоинтенсивных посторонних пиков. Таким образом, для исследования использовали все растворы серий Б и В, а также Г1-ГЗ, Д1 и Д2. Исследования показали, что состав подвижной фазы практически не влияет на качество масс-спектров.

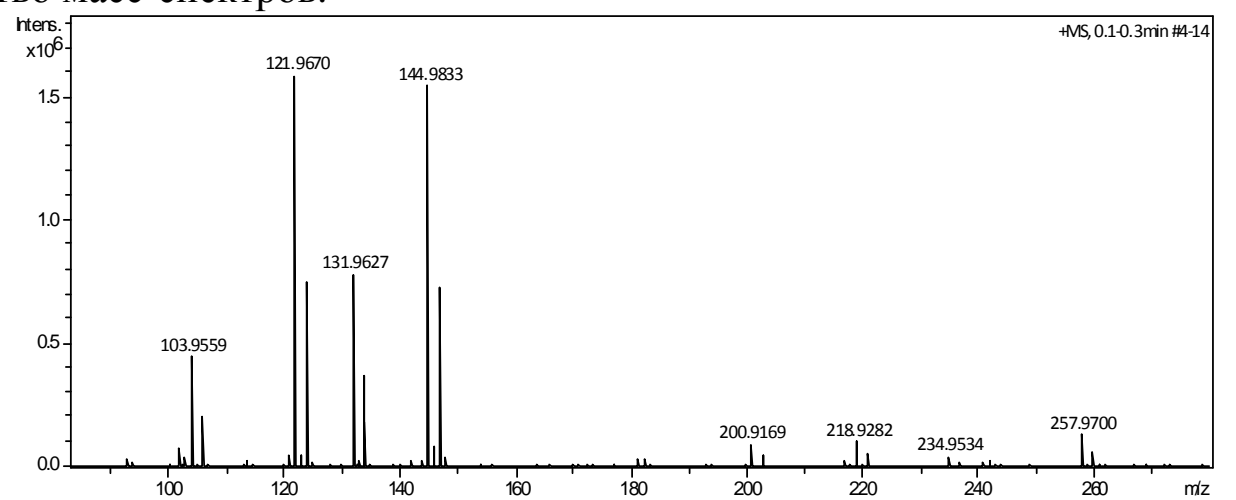

Рис. 1. Масс-спектр раствора сульфата меди с концентрацией $10^{-2} \mathrm{M}$ в режиме регистрации отрицательных ионов.

На рисунке 1 приведён масс-спектр ESI-MS раствора чистого сульфата меди. Видно, что масс-спектр состоит в основном из медьсодержащих пиков с характерным для меди изотопным распределением. Расстояние между пиками соответствует присоединению молекул воды и катионов натрия и калия, которые присутствуют в используемой для пробоподготовки воде.

При использовании растворов тирозина с высокой концентрацией сульфата меди (более $10^{-3}$ моль/дм ${ }^{3}$ ) был получен масс-спектр изображённый на рисунке 2. Ион с массой 182.0830 Да соответствует протонированному иону тирозина. В массспектре наблюдается довольно нехарактерная для метода МАЛДИ фрагментация молекулярного иона тирозина. Так ион с массой 165.0562 Да соответствует продукту ухода аминогруппы из тирозина, затем происходит дегидратация этого иона с образованием иона с массой 147.0455 Да. Кроме того происходит параллельный процесс декарбоксилирования тирозина с образованием иона с массой 136.0770 Да. Следует 
отметить, что образование протонированного димера тирозина (масса 363,1607 Да) в значительной степени подавлено, иные ионы не образуются.

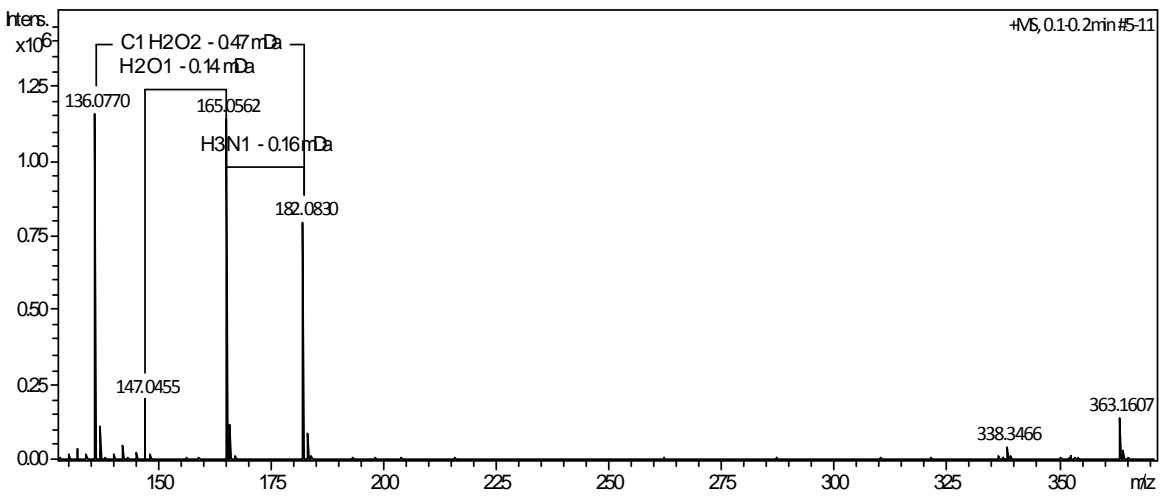

Рис. 2. Масс-спектр раствора Д2 тирозина в режиме регистрации положительных ионов.
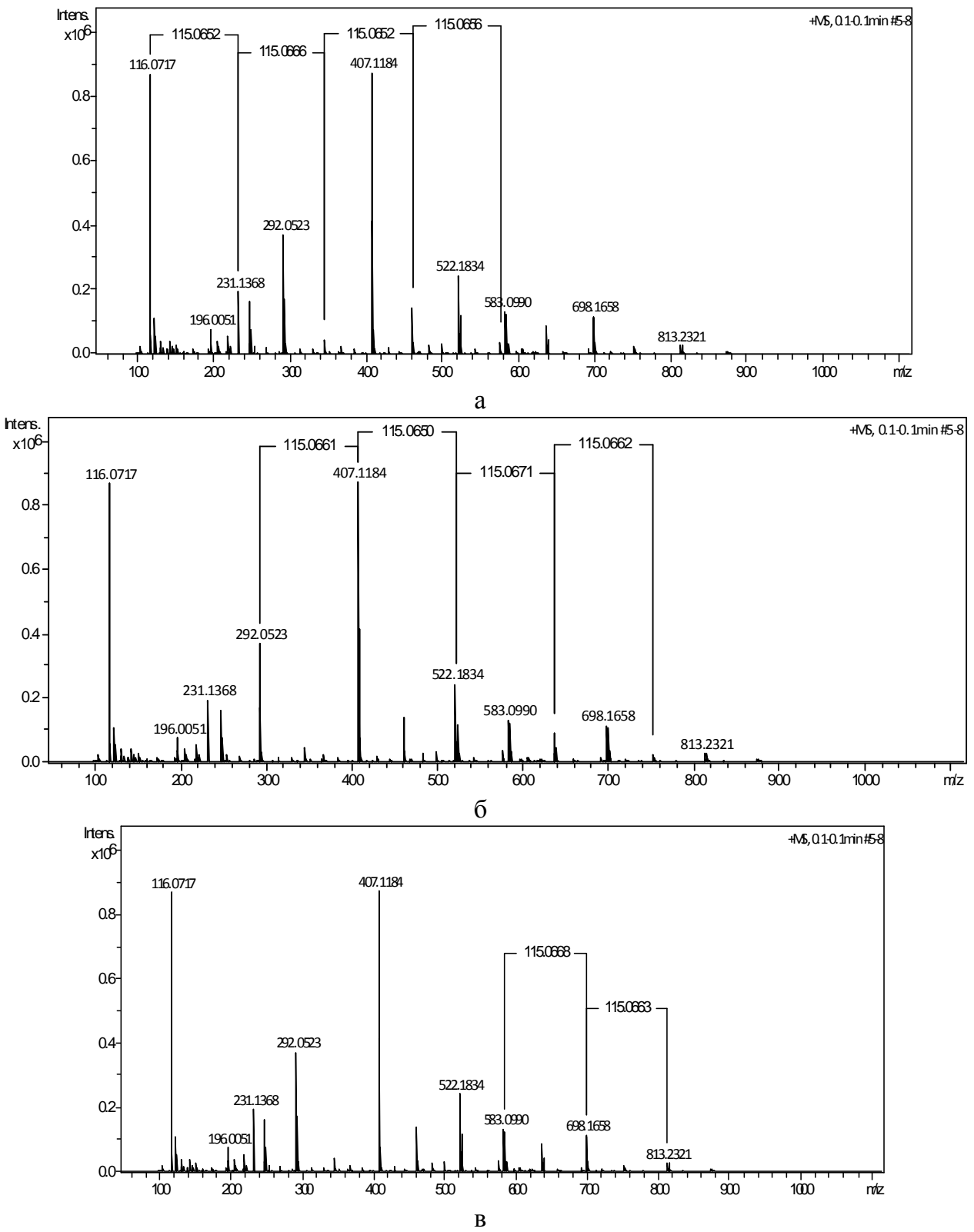

Рис. 3. Масс-спектр раствора ГЗ пролина с выделенными рядами кластерообразования чистого пролина (а), пролина с катионом меди (б), пролина с двумя атомами меди (в). 
При исследовании неароматического пролина в значительной мере идёт кластерообразование с медью. На рисунке 3 можно чётко выделить три направления кластерообразования:

1. Рисунок 3a: агломерация молекул протонированной аминокислоты -

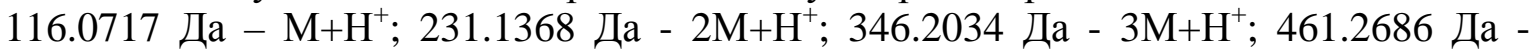
$4 \mathrm{M}+\mathrm{H}^{+} ; 576.3342$ Да $-5 \mathrm{M}+\mathrm{H}^{+}$.

2. Рисунок 3б: агломерация молекул $\mathrm{M}+\mathrm{Cu}-$ присоединение двух атомов меди к молекуле аминокислоты невозможно, поэтому ряд начинается с пика массой 292.0523 Да, соответствующего иону $2 \mathrm{M}+\mathrm{Cu}^{+}$, затем идут ионы с массами 407.1184; $522.1834 ; 637.2506$ и 752.3168 Да соответствующие кластерным ионам 2M+Cu; $3 \mathrm{M}+\mathrm{Cu} ; 4 \mathrm{M}+\mathrm{Cu} ; 5 \mathrm{M}+\mathrm{Cu}$. Следует отметить, что образование кластеров в этом случае доходит только до пентамера аминокислоты.

3. Рисунок 3в: агломерация аминокислоты с двумя атомами меди - в данном случае ионов всего два, но они довольно крупные. Это ион с массой 583.0990 Да $\left(4 \mathrm{M}+2 \mathrm{Cu}^{+}\right)$и ион с массой 813.2321 Да $\left(5 \mathrm{M}+2 \mathrm{Cu}^{+}\right)$. Характерно, что кластерообразование снова заканчивается пентамером аминокислоты. Известно, что два атома меди хорошо координируют четыре крупных лиганда (например, ацетат). Этим, видимо, объясняется наличие таких крупных ионов и отсутствие подобных структур меньшей массы.

\section{Заключение}

Проведено систематическое исследование кластерообразования аминокислот методом ESI-MS в присутствии соли меди. Показано, что для ароматических аминокислот (тирозина, триптофана) наиболее характерны процессы фрагментации молекулы аминокислоты и менее характерны процессы агломерации и кластерообразования крупных ионов. На примере пролина показано, что наиболее интенсивно кластерообразование проходит в простых неароматических аминокислотах. Выделено три направления кластерообразования. Таким образом, добавление неорганических солей значительно влияет на состав масс-спектров и может применяться для поиска следовых количеств аминокислот в растворах сложных смесей как с применением хроматографического разделения так и при прямом вводе.

\section{Список литературы/References}

1. Lin L., Weng C., Chen Q., Nuclear Instruments and Methods in Physics Research Section $B$ : Beam Interactions with Materials and Atoms, Vol. 414, No 1, pp. 79-83.

2. Kozlov A.N., Konovalov V.S. Communications in Nonlinear Science and Numerical Simulation, 2017, Vol. 51, pp. 169-179.

3. Murakami K., Sato A., Hashimoto K., Fujino T., Chemical Physics, 2013, Vol. 419, pp. 37-43.

4. Pytskii I. S., Petukhova G.A., Kuznetsova E.S., Buryak A.K., Surface innovations, 2017, Vol. 5, No 3, pp. 179-187.
5. Kuznetsova E.S., Pytskij I.S., Buryak A.K., Sorbtsionnye i khromatograficheskie protsessy, 2018, Vol. 18, No 2, pp. 238-242.

6. Tugarova A.V., Kamnev A.A., Talanta, 2017, Vol. 174, pp. 539-547.

7. Pytskii I.S., Buryak A.K. Protection of metals and physical chemistry of surfaces, 2014, Vol. 50, No 1, pp. 121-125.

8. Kuznetsova E.S., Uleanov A.V., Buryak A.K., J. of Phys. Chem.. 2009, Vol. 83, No 4, pp. 638-642. 
Кузнецова Елена Сергеевна - старший научный сотрудник лаборатории синтеза и исследования сорбентов, к.х.н. Институт физи- ческой химии и электрохимии имени А.Н. Фрумкина РАН, Москва

Пыцкий Иван Сергеевич - старший научный сотрудник лаборатории физикохимических основ хроматографии и хроматомасс-спектрометрии, к.х.н. Институт физической химии и электрохимии имени А.Н. Фрумкина РАН, Москва

Буряк Алексей Константинович - заведующий лабораторией физико-химических основ хроматографии и хромато-массспектрометрии, проф, д.х.н. Институт физической химии и электрохимии имени А.Н. Фрумкина РАН, Москва
Kuznetsova Elena S. - PhD (chemistry), laboratory of synthesis and investigation of sorbents, Institute of Physical chemistry and electrochemistry, Moscow

Pytskii Ivan S. - PhD (chemistry), laboratory of physical-chemical basics of chromatography and chromato-mass-spectrometry, Institute of Physical chemistry and electrochemistry, Moscow. E-mail: ivanpic4586@gmail.com

Buryak Alexey K. - prof., grand $\mathrm{PhD}$ (chemistry), laboratory of physical-chemical basics of chromatography and chromato-mass-spectrometry Institute of Physical chemistry and electrochemistry, Moscow 